\title{
Cardiovascular imaging: Quiz case
}

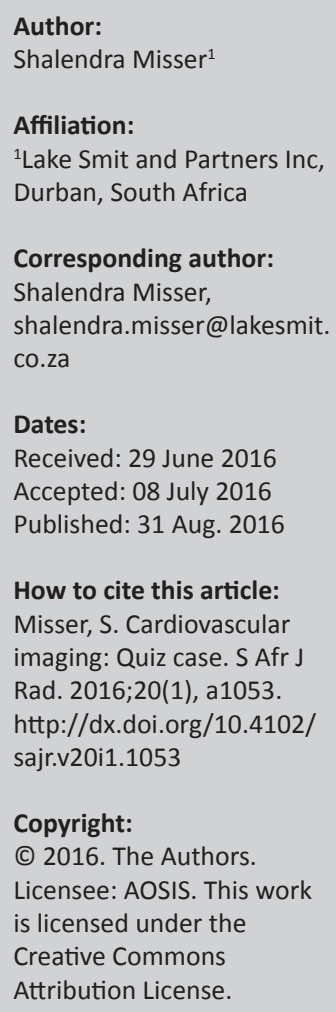

\section{Copyright:}

(c) 2016. The Authors.

Licensee: AOSIS. This work

is licensed under the

Creative Commons

Attribution License.

A 32-year-old lady presented with shortness of breath, (New York Heart Association [NYHA] grade $2-3$ ), becoming progressively worse, associated with cough, chest pain and constitutional symptoms. She underwent extensive investigations shown in the series of images including chest radiograph, abdominal sonar, computed tomography of chest and abdomen as well as a cardiac magnetic resonance imaging study.

Describe the relevant imaging findings and formulate the most appropriate clinical diagnosis.

Please submit your response to shalendra.misser@lakesmit.co.za no later than 30 September 2016.

The winning respondent will receive a R2000 award from the RSSA.

A detailed diagnosis and discussion will be presented within SAJR, Volume 18, 2016.

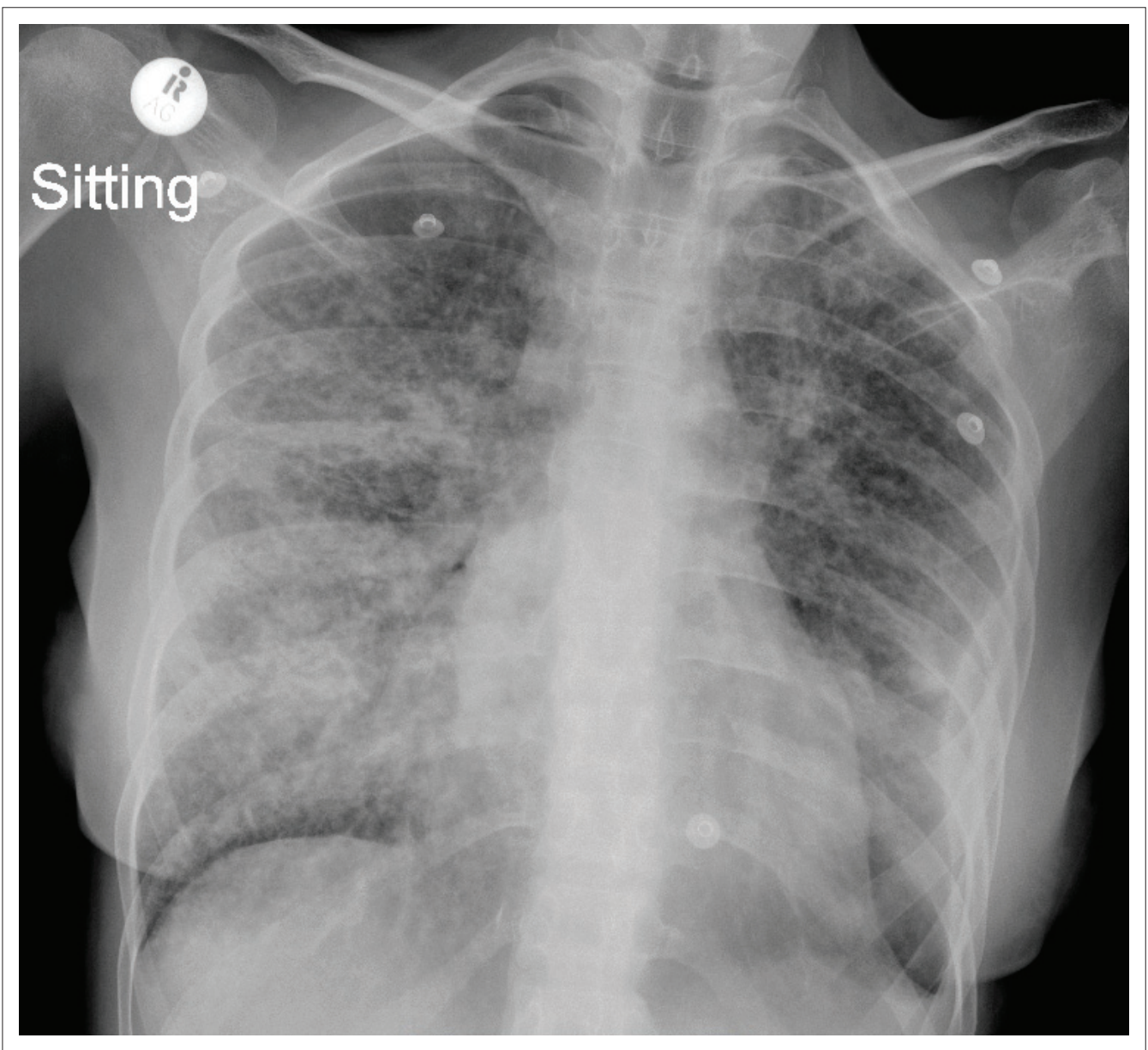

FIGURE 1: Chest radiograph performed on admission. 

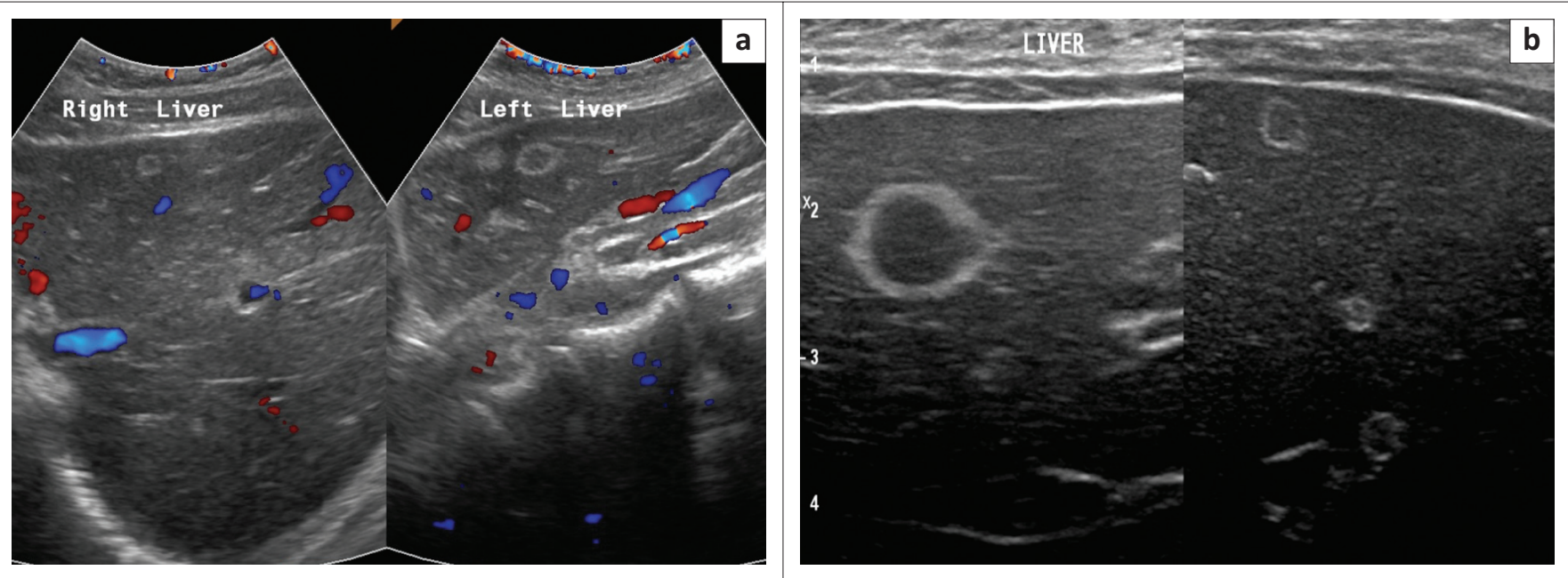

FIGURE 2: Sonar image of the liver: (a) in colour duplex; (b) in B-mode higher frequency.
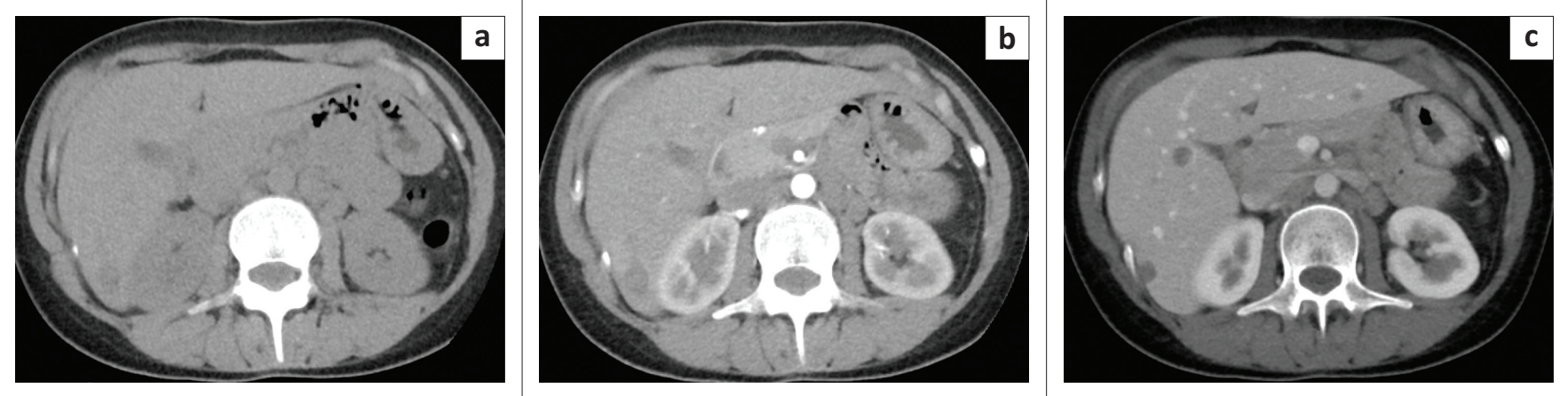

FIGURE 3: Axial CT images of the upper abdomen: (a) pre-contrast study; (b) arterial phase; (c) portal venous phase.
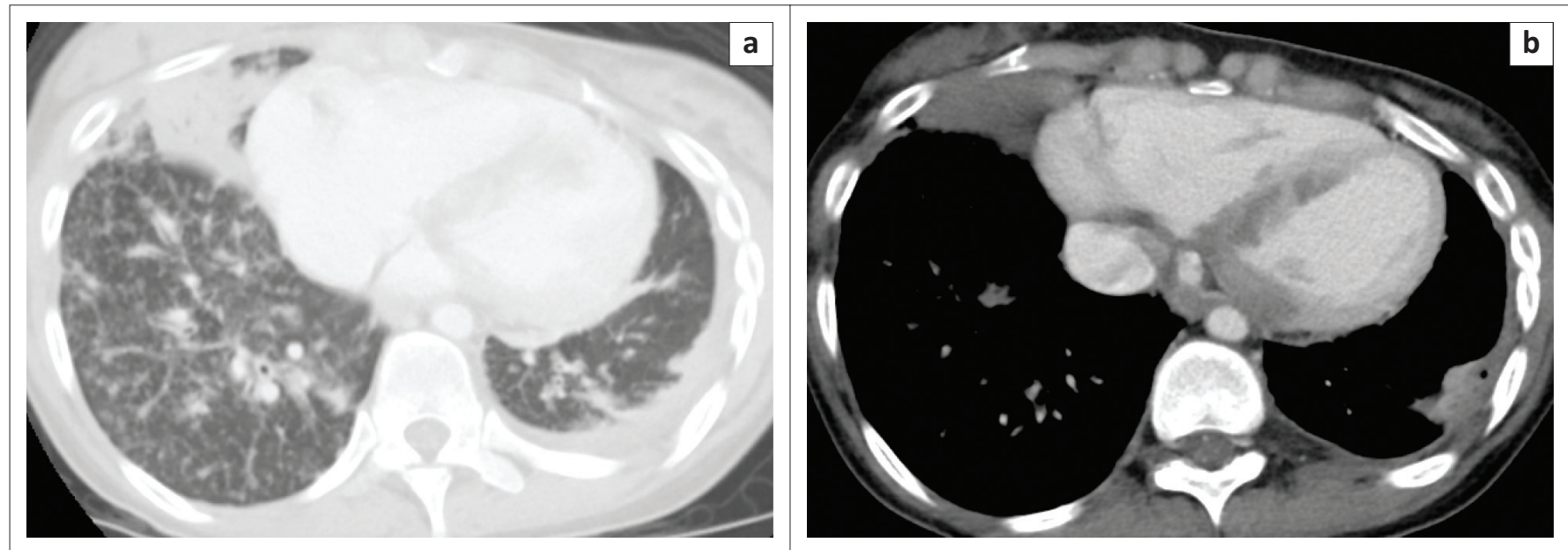

FIGURE 4: Axial CT images of the lower lung fields (a) and at the level of the left ventricle (b). 


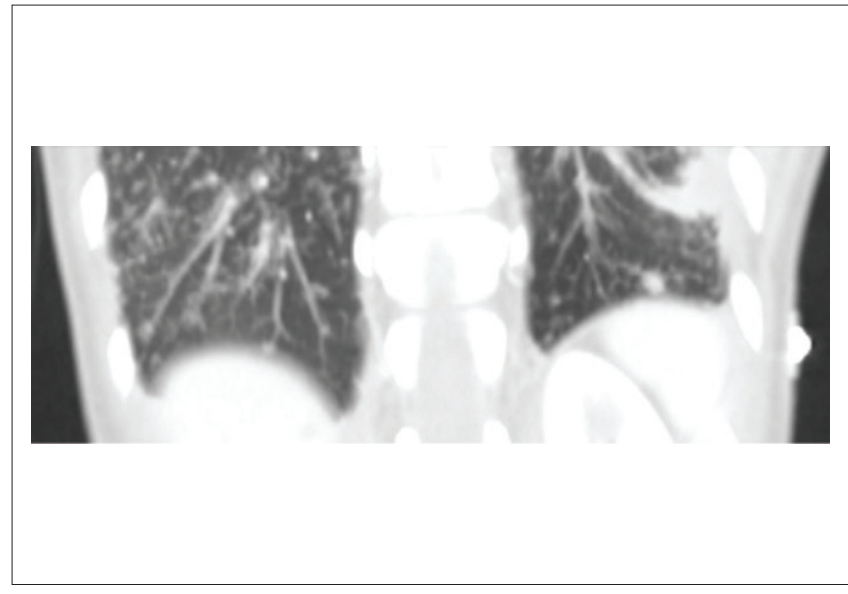

FIGURE 5: Coronal reformatted CT images of the lower lung fields.

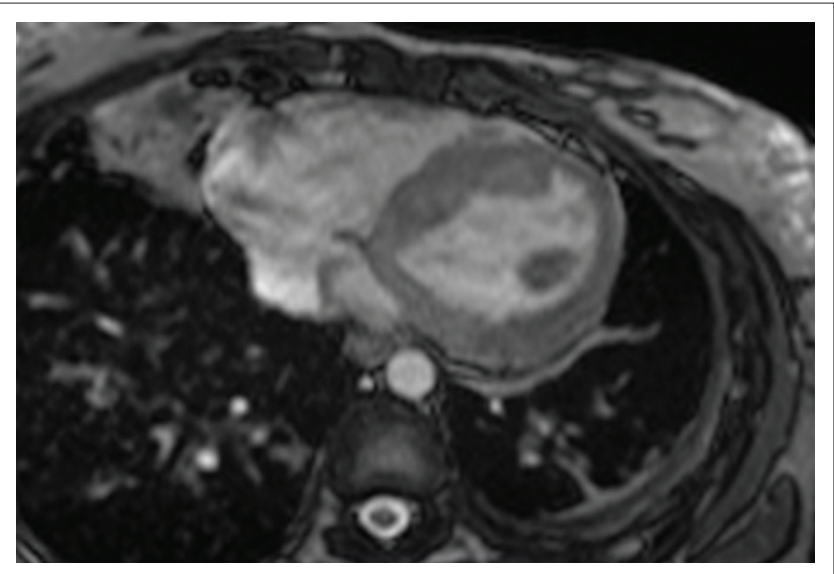

FIGURE 6: Axial dual chamber cardiac T2-weighted MRI image.
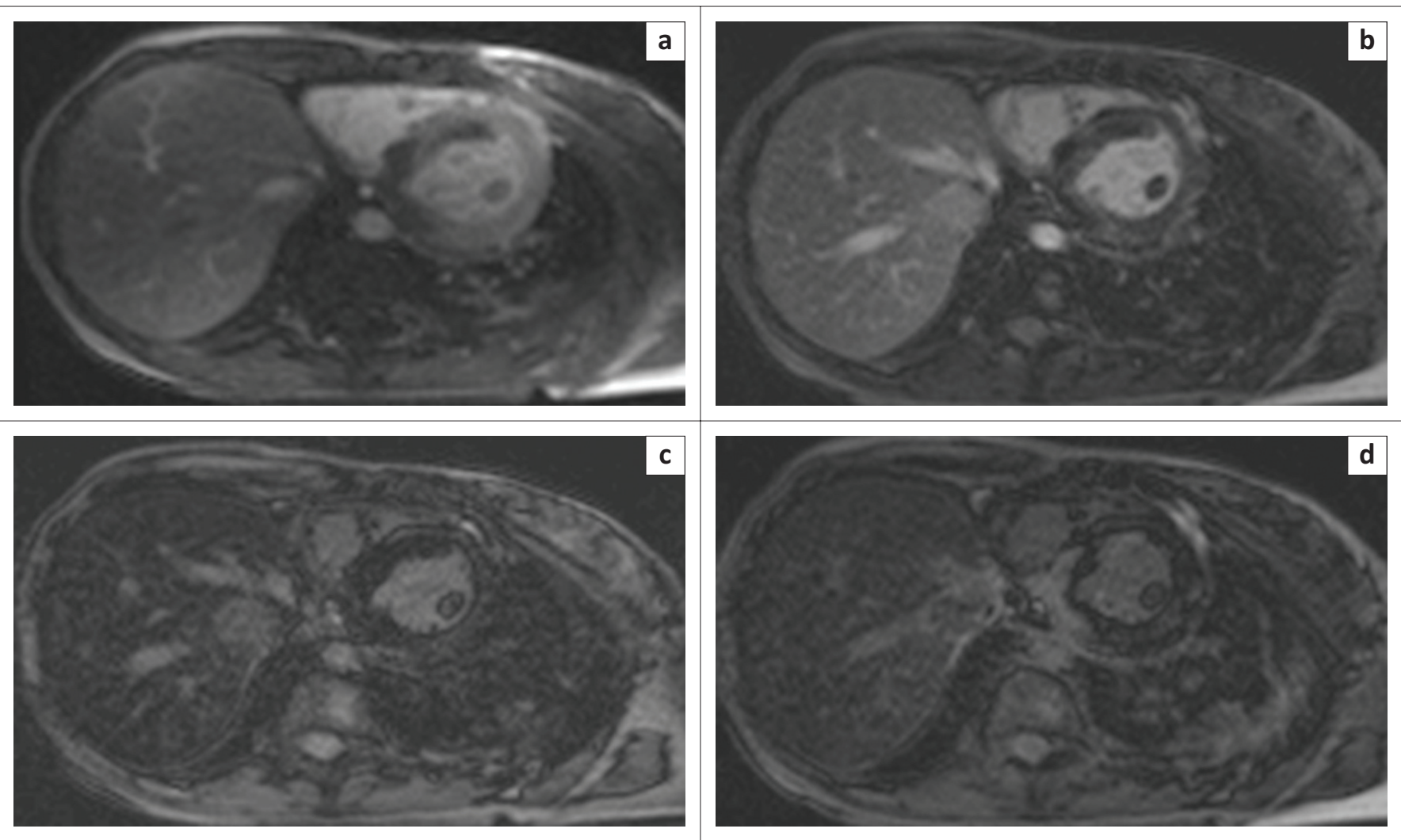

FIGURE 7: Axial post-contrast TRUFI MR images performed at time intervals after intravenous gadolinium injection: (a) Dynamic; (b) 2 minutes; (c) 5 minutes; (d) 12 minutes delay. 